\title{
A IMPORTÂNCIA DE NOVAS METODOLOGIAS DE ENSINO-APRENDIZAGEM EM CURSOS UNIVERSITÁRIOS NA ÁREA DA SAÚDE
}

Denise Vasconcelos de Jesus Ferrari, Luciana Vasconcelos de Jesus Souza, Carmen Lúcia Dias.

Universidade do Oeste Paulista - UNOESTE, Mestrado em Educação. Presidente Prudente, SP. E-mail: denisevi@hotmail.com

\section{RESUMO}

Este artigo busca apresentar uma breve análise da importância da utilização de novas metodologias de ensino-aprendizagem para a graduação na área da saúde, visando, com a contribuição de alguns teóricos, pontuar aspectos relativos a peculiaridade da área da saúde quanto a evolução constante de novas tecnologias e processos, que demandam novos aprendizados constantes, e relações sociais que exigem do futuro profissional uma maior interdisciplinaridade e assim necessita de método de ensino que atenda a estas necessidades que a realidade atual exige, e afim de exemplificar esta situação é descrita a metodologia ativa de ensino-aprendizagem, que alinha este processo. Conclui-se que esta metodologia, apesar de não ser a solução, se apresenta como uma importante alternativa que se adequa à situação atual diante de tantas demandas por um profissional competente, com possibilidades de aplicação e resultados satisfatórios conforme tem demonstrado diversos programas de ensino.

Palavras chave: Metodologias ativas. Ensino-aprendizagem. Área da saúde.

\section{THE IMPORTANCE OF TEACHING METHODS AND LEARNING IN NEW UNIVERSITY COURSES IN HEALTH AREA}

\begin{abstract}
This article seeks to present a brief analysis of the importance of using new teaching and learning methodologies for graduation in health, aimed, with the contribution of some theoretical, at scoring aspects of the uniqueness of health care as the constant evolution of new technologies and processes, which require new constant learning, and social relations that require professional future greater interdisciplinarity and thus requires teaching method that meets these needs that the present situation requires, and in order to illustrate this situation is described in the active methodology of teaching and learning, lines this need. We conclude that this approach, although not the solution presents itself as an important alternative to suit the current situation with so many demands for a competent professional, with application possibilities and satisfactory results as has been shown many educational programs.
\end{abstract}

Keywords: Active methodology. Teaching and learning. Health area. 


\section{INTRODUÇÃO}

Em busca de um processo de ensino e de aprendizagem que possa corresponder as necessidades dos professores e dos alunos para a construção do conhecimento, diversos métodos, abordagens e recursos tem sido avaliados e implantados; assim constantemente criando modelos e programas em que estes lados sejam atendidos, e que possam ter sucesso.

Por um lado temos o professor e seu papel neste processo, e sua constante necessidade de formação e preparação. Enricone (2001, p.41), afirma que "há necessidade de priorizar as discussões sobre a formação do professor universitário, com vistas a inovar suas formas de ensinar para dialogar com a incerteza" fator este que é ponto chave para o ensino na saúde. Esta busca torna o processo efetivo e, diante da tecnologia tornando a mudança cada vez mais rápida, gerando assim inúmeros questionamentos sobre a ação de ensinar, suas características e circunstancias e também suas consequências.

[...] a quem é ensinado o quê, como, por quem e em que circunstâncias; como, por quem e através de que estruturas, instituições e processos são definidas estas coisas, como é que são governadas, organizadas e geridas; quais são as consequências sociais e individuais destas estruturas e processos? (DALE, 2004 p. 439).

Os questionamentos descritos por Dale (2004) orientam a busca por como gerir o ensinoaprendizagem e a elaboração de processos estruturados para a área da saúde fundamentados em protocolos dos mais diversos, que vão da visão macro, ou seja, generalista até a visão pontual, específica, "microscópica" dos problemas e soluções, trazendo assim desafios para esta alta gama de cenários práticos e profissionais, transportados para os currículos dos cursos de saúde.

Novos desafios se impõem nos cenários atuais da educação e currículos universitários altamente complexos. O acúmulo exponencial de conhecimentos e a incorporação crescente de tecnologias de aplicação nas várias áreas da saúde impulsionaram para uma formação médica fragmentada em campos altamente especializados e a busca da eficiência técnica. (SOUZA; IGLESIAS; FILHO, 2014 p. 284).

Assim é necessidade capital a busca por estes métodos, que orientem e evoluam com a busca pelo conhecimento, a fundamentação e a base das disciplinas e a aplicação prática de forma efetiva deste conhecimento promovendo assim a aprendizagem significativa para os futuros profissionais da saúde. São diversas metodologias que podem ser aplicadas, e não é objetivo deste trabalho descrever todos os possíveis modelos, nem tampouco criar uma metodologia inovadora ou a descoberta de novas formas de aprendizado, mas sim de discutir e instigar a busca por estas metodologias. Aqui apresentaremos um exemplo de metodologia que está realizando este papel, sendo eficaz em gerar este conhecimento e eficiente em cumprir com os resultados para a área da saúde.

\section{METODOLOGIA}

O presente artigo tem como base metodológica a pesquisa bibliográfica que Volpato (2003), define como sendo uma pesquisa que reúne ideias advindas de diferentes fontes o que proporciona nova possibilidade de discussão de um tema já conhecido. Salvador (1991) descreve como aporte teórico a revisão de literatura especializada, com autores que propõem uma discussão acerca de questões pertinentes, neste caso, a análise de novas metodologias de ensino em relação ao processo de aprendizagem em nível de graduação na área da saúde. 


\section{DISCUSSÃO}

O processo de aprendizagem é complexo, com muitas nuances e especificidades para a educação e os currículos em saúde. O acúmulo constante de conhecimento e a aplicação de cada vez mais tecnologia faz com que haja a necessidade inerente da busca por métodos e modelos que visem garantir não só o conhecimento teórico ou técnico mas sim a convergência para um conhecimento especializado com aplicação prática, instigando a busca de soluções e constante pesquisa gerando assim conhecimento científico.

Gil (2005, p.57), conceitua inicialmente aprendizagem como "à aquisição de conhecimentos ou ao desenvolvimento de habilidades e atitudes em decorrência de experiências educativas, tais como aulas, leituras, pesquisas etc." e a partir deste ponto é que buscamos métodos para atingir os objetivos reais, com a produção de conhecimento efetivo, que possa ser aplicado e principalmente propagado, de forma ágil e eficiente.

Souza e cols. destacam que:

Em substituição aos métodos tradicionais, e particularmente passivos, no processo de transformação dos modelos de educação, fortaleceram as considerações acerca: das peculiaridades de aprendizado do adulto e suas relações com a sociedade; da prática das metodologias ativas; e da apropriação de novos recursos das tecnologias de informação e comunicação. (SOUZA, IGLESIA; FILHO, 2014 p. 285).

Portanto, tem-se que observar que há necessidade de transformação na educação superior, em especial na área da saúde, evoluindo do processo tradicional de aprendizagem, para modelos que atendam a necessidade deste "novo" profissional, que tem características voltadas para a inovação, pesquisa e principalmente para a resolução de problemas.

No processo de aprendizagem não importa qual metodologia seja aplicada, porém observa-se que ela caminha por fatores ligados a complexidade do problema, e por diferenças individuais, ou seja, cada um tem uma carga de conhecimento adquirido, competências, atitudes e experiências que vem desde a infância, e estes fatores alteram a forma de aprender do indivíduo, que pode ser demonstrado na seguinte situação apresentada por Gil:

Após ser dado determinado problema de Matemática em sala de aula, alguns alunos tendem a concluí-lo mais rapidamente que outros. Alguns alunos são mais rápidos em levantar as mãos para responder a uma pergunta, enquanto outros são mais lentos. Alguns alunos lembram-se facilmente da matéria ministrada no dia anterior, enquanto outros terão se esquecido e precisarão recordá-la. (GIL, 2005 p. 58)

Outros fatores importantes são a motivação, um fator que impulsiona o aprendizado, e também a vontade, o desejo de conhecimento, de realização, que de acordo com Gil (2005 p. 58) "convém considerar que a motivação é algo interior. As pressões externas podem aumentar o desejo de aprender, mas é necessário primeiramente que se queira aprender". A reação, que é o estimulo de resposta a algo, uma dúvida, uma ânsia, um problema e outros demais fatores, que geram esta ação de responder aquilo que o instiga. Também neste processo temos a memorização, que é a evocação do que foi aprendido, tendo uma relação direta com as diferenças individuais, e com a motivação, entre outros.

A partir deste entendimento devemos colocar no ambiente de ensino-aprendizagem os atores deste processo, que são o professor e o aluno, neste caso especificamente o aluno do ensino superior na área da saúde. Uma relação ambientada em diversos aspectos, que demanda 
uma constante comunicação e um relacionamento de busca, ou seja, uma relação que tenha evolução constante, para que o propósito deste relacionamento seja atingido, que é a aprendizagem, através de um ensino efetivo e marcado não apenas pela aquisição de conteúdo. Segundo Masetto (2003, p. 23) no ensino superior "além dos conhecimentos necessários, habilidades, competências e análise e desenvolvimento de valores" são essenciais e necessários, pois eles que vão gerar a evolução do profissional, do então aluno, que irá atingir seus objetivos e criar para si mais que conhecimento, e sim uma gama de aptidões necessárias para sua atividade.

Neste contexto as novas metodologias se encaixam proporcionando este algo a mais, este estímulo para a aprendizagem, atendendo a necessidade eminente da inovação e da aquisição das competências necessárias para atuar na atividade de sua escolha.

A metodologia ativa, diferente da tradicional tem como foco a relação de aprendizado, e a ênfase nesta relação, trazendo o aluno como agente, não apenas como ouvinte ou passivo do processo, isso faz com que haja uma maior interação e consequentemente que o processo de ensino e de aprendizagem se torne mais dinâmico.

Souza, Iglesias e Filho (2014, p.285) destacam que "entre as principais características, os métodos inovadores de ensino-aprendizagem mostram claramente o movimento de migração do "ensinar" para o "aprender", o desvio do foco do docente para o aluno, que assume a corresponsabilidade pelo seu aprendizado". Ainda os autores (2014) destacam algumas comparações importantes entre as metodologias ativas e a tradicional de ensino-aprendizagem, onde a metodologia ativa permite a construção de estratégias que podem demonstrar como se faz, ou seja, que buscam não apenas demonstrar habilidades, repetições, mas sim a pratica em busca da excelência. Outro fator importante é o papel do professor, que é de interação, e não de transmissão apenas, e principalmente neste modelo o papel do aluno, que deixa de ser apenas passivo, absorvendo informações, e passa a ser ativo, sendo responsável pelo seu próprio ensino.

A Política Nacional de Educação Permanente em Saúde (PNEEP) (BRASIL, 2009), em seu texto busca o estímulo ao conhecimento dos problemas do mundo atual (nacional e regional) e a prestação de serviço especializado à população, estabelecendo com ela uma relação de reciprocidade. Isto quer dizer que ações públicas também observam esta evolução e demonstram caminhar ao encontro de um modelo mais interativo e de maior responsabilidade do aluno.

Segundo Melo e Sant'Ana (2012):

O uso dessa Metodologia Ativa confronta o ensino tradicional das faculdades, caracterizado por retenção de informação, disciplinas fragmentadas e avaliações que exigem memorização, podendo levar os estudantes à passividade e aquisição de uma visão estreita e instrumental do aprendizado, promovendo carências de constante atualização.

O grande desafio da Metodologia Ativa é aperfeiçoar a autonomia individual e uma educação capaz de desenvolver uma visão do todo transdisciplinar, que possibilite a compreensão de aspectos cognitivos, afetivos, socioeconômicos, políticos e culturais, constituindo uma prática pedagógica socialmente contextualizada (MELO; SANT'ANA, 2012, p. 329).

Ela não é a solução, nem o melhor modelo, mas sim é uma importante alternativa que se adequa à situação atual, por uma demanda de profissionais altamente qualificados, com possibilidade de aplicação e com resultados satisfatórios, desde que aplicada de forma correta, e planejada com coerência.

Para exemplificar a importância das novas metodologias podemos citar a metodologia da problematização, uma metodologia que, segundo Berbel (1999, p. 27): "foi proposta, inicialmente, por Bordenave e Pereira e seu ponto de partida é o pensamento freireano, uma vez que leva em conta a realidade do sujeito (estudante), sua experiência e conhecimentos prévios" baseando-se 
inicialmente na observação da realidade concreta, determinando pontos chave e teorizando os aspectos observados, com a posterior busca por hipóteses de solução do problema e tentar aplicar a realidade a estas hipóteses. Sendo assim, muito mais consistente em suas ações de ensinoaprendizagem, demandando uma motivação e esforço de todas as formas para o sucesso do processo.

\section{CONCLUSÃO}

Novas metodologias de ensino-aprendizagem são um desafio constante, não somente para a área da saúde, mas para o ensino como um todo, pois a evolução da sociedade, a mudança provocada por esta evolução, a interação de fatores desde ambientais, socioeconômicos, político legais e tecnológicos, interagem com o como aprendemos e como ensinamos. A área da saúde é um reflexo vivo deste aspecto, pois lida com fatores limites da sociedade, buscando sempre o melhor e sempre resolver problemas, muitos deles críticos, demonstrando assim a importância da busca por modelos e metodologias que se adequem, sejam coerentes, e deem possibilidade de melhoria, não apenas no conteúdo, ou no currículo, mas sim a todo o processo acadêmico.

\section{REFERÊNCIAS}

BERBEL, N. Metodologia da problematização: fundamentos e aplicações. Londrina: Ed. UEL, 1999.

BRASIL. Política Nacional de Educação Permanente em Saúde. 2009. Disponível em: http://bvsms.saude.gov.br/bvs/publicacoes/politica_nacional_educacao_permanente_saude.pdf. Acesso em 16 de março de 2016.

DALE, R. Globalização e educação: demonstrando a existência de uma "cultura educacional mundial comum" ou localizando uma "agenda globalmente estruturada para a educação?" Tradução: Antônio M. Magalhães. Educação e Sociedade, Campinas, v. 25, n. 87, maio/ago. 2004.

ENRICONE, D. (Org). Ser professor. Porto Alegre: EDIPUCRS, 2001.

GIL, A. C. Metodologia do ensino superior, 4. ed. Atlas, 2005. VitalSource Bookshelf Online.

MASETTO, M. Competência pedagógica do professor universitário. São Paulo, Summus 2003.

MELO, B. C.; SANT'ANA, G. A prática da Metodologia Ativa: compreensão dos discentes enquanto autores do processo ensino aprendizagem. Brasília, vol. 23, no 4, p. 327-339, jun. 2012 Disponível em: http://www.escs.edu.br/pesquisa/revista/2012Vol23_4_5_ApraticaMetodologiaAtival.pdf.

SALVADOR, A.D. Métodos e técnicas de pesquisa bibliográfica. Porto Alegre: Sulina Editora, 1991.

SOUZA, C. S., IGLESIAS, A. G., FILHO, a. p., Estratégias inovadoras para métodos de ensino tradicionais - Aspectos gerais. Ribeirão Preto, v. 47, n. 3, p. 284-292, jun. 2014. Disponível em: http://revista.fmrp.usp.br/2014/vol47n3/6_Estrategias-inovadoras-para-metodos-de-ensinotradicionais-aspectos-gerais.pdf. Acesso em 18 de março de 2016.

VOLPATO, G.L. Publicação científica. 2. ed. Botucatu: Tipomic ,2003. 